\title{
A prospective cohort study of dietary indices and incidence of epithelial ovarian cancer
}

\author{
Jing Xie ${ }^{1,2}$, Elizabeth M Poole ${ }^{1,2}$, Kathryn L Terry ${ }^{2,3}$, Teresa T Fung ${ }^{4}$, Bernard A Rosner ${ }^{1,5}$, Walter C Willett ${ }^{1,2,6}$ \\ and Shelley S Tworoger ${ }^{1,2^{*}}$
}

\begin{abstract}
Background: Several dietary indices have been developed to measure overall diet quality, including the Healthy Eating Index-2005 (HEl-2005), which measures adherence to the 2005 Dietary Guidelines from the USDA; the Alternative Healthy Eating Index-2010 (AHEl-2010), which is based on foods and nutrients predictive of chronic disease risk; and the Alternate Mediterranean Diet Score (aMDS), which is an index that characterizes traditional food patterns of Mediterranean countries. Few studies have evaluated diet quality and ovarian cancer risk.

Methods: We assessed the associations of the HEI-2005, AHEI-2010, and aMDS with risk of epithelial ovarian cancer prospectively among women in the Nurses' Health Study. We used Cox proportional hazards models, adjusting for known ovarian cancer risk factors.

Results: During 24 years of follow-up, we documented 696 incident epithelial ovarian cancer cases among 82,948 women with diet information. The multivariate adjusted hazard ratios (95\% confidence interval; Ptrend) of epithelial ovarian cancer comparing the highest with the lowest quintile were $1.03(0.80-1.34 ; 0.77)$ for the AHEI-2010, 0.85 (0.65-1.12; 0.57) for the HEl-2005, and $0.91(0.71-1.18 ; 0.44)$ for the aMDS.
\end{abstract}

Conclusions: We did not observe any clear association of three diet quality scores with ovarian cancer risk. Further work should other metrics of evaluating diet quality that may be more relevant cancer risk.

Keywords: Alternative healthy eating index, Healthy eating index, Mediterranean diet score, Dietary pattern, Ovarian cancer, Prospective cohort, Epidemiology

\section{Introduction}

Ovarian cancer is the fifth leading cause of cancer death for women in the U.S. [1]. There are substantial geographic differences in ovarian cancer incidence rates across the world, with the highest age-adjusted incidence rates in developed countries (greater than 10 per 100,000), except for Japan (6.4 per 100,000) [2]. One study reported that daughters of Japanese immigrants to the US had ovarian cancer incidence rates approaching the rates of American Caucasians [3]. This suggests that non-genetic and potentially modifiable risk factors, including dietary factors, may influence ovarian carcinogenesis. While

\footnotetext{
* Correspondence: nhsst@channing.harvard.edu

${ }^{1}$ Channing Division of Network Medicine, Department of Medicine, Brigham and Women's Hospital and Harvard Medical School, 181 Longwood Avenue, Boston, MA 02115, USA

2Department of Epidemiology, Harvard School of Public Health, Boston, MA, USA

Full list of author information is available at the end of the article
}

ovarian cancer risk factors, including lack of oral contraceptive use, lack of tubal ligation, postmenopausal hormone therapy (HT), nulliparity, and a family history of breast or ovarian cancer [2], have been identified, few dietary factors have been consistently associated with the disease [4].

Prior studies of diet and ovarian cancer generally have evaluated only one food or nutrient at a time (e.g. [5-10]). Diet quality scores are based on a priori defined dietary patterns and are designed to evaluate an individual's overall diet, usually derived from adherence to dietary guidelines. This measurement considers dietary intake as an overall pattern, rather than evaluating individual nutrients or food groups, which could lead to important information that may represent new pathways for prevention. While most diet quality scores were developed to predict cardiovascular outcomes [11,12], 
there is potential for these scores to predict other outcomes, such as ovarian cancer, that may have shared etiologic pathways like inflammation [13-15]. Only one study has evaluated a diet quality score and ovarian cancer risk in a population-based case-control study; no association was observed between the Healthy Eating Index 2005 (HEI-2005) with risk [16].

Using Food Frequency Questionnaire (FFQ) data collected from women in the Nurses' Health Study (NHS), we prospectively examined the associations between three diet quality scores and risk of ovarian cancer. The dietquality scores examined were the Alternative Healthy Eating Index 2010 (AHEI-2010), HEI-2005, and the Alternate Mediterranean Diet Score (aMDS).

\section{Methods \\ Study population}

The NHS is a prospective cohort initiated in 1976, when 121,700 female registered nurses, 30 to 55 years of age and residing in 11 U.S. states, completed an initial questionnaire. In 1984, we used a comprehensive FFQ to collect dietary data from participants. The cohort has been followed by biennially mailed questionnaires to update covariate information and ascertain non-fatal incident diseases. Deaths in the cohort are usually reported by family or postal authorities. We also search for names of non-responders in the National Death Index $[17,18]$. The follow-up rate through June 2010 of women who completed the 1984 FFQ was $97 \%$ of the potential personyears. Completion of the self-administered questionnaire was considered to imply informed consent. This analysis was approved by the institutional review board at the Brigham and Women's Hospital.

\section{Dietary measurement and FFQ}

Dietary information was measured by a self-administered semi-quantitative, 131-item FFQ, which was completed every 2 to 4 years in the cohort. For each food, a portion size was given and women were asked to choose from 9 intake frequencies, from never to $\geq 6$ servings per day averaging over the prior year's intake. Consumption of cold breakfast cereals, cooking oils, margarines, and multiple vitamins was specified by brand. The validity of our FFQ was evaluated by comparison with diet records in 192 NHS women; the average correlation for all foods was 0.63 [19-21].

\section{Diet-quality scores}

The HEI-2005 measures adherence to the USDA Dietary Guidelines established in 2005, and is based on dietary recommendations to ensure adequate nutrient intake [22]; the components include total fruit, total vegetables, total grains, milk, and meat and beans (Additional file 1:
Table S1). Additional components were created to represent whole fruit, dark green and orange vegetables and legumes, whole grains, and oils. The score ranges from 0 to 100 . The HEI-2005 is a valid measure of diet quality in that the components are not strongly correlated with the overall score and that "exemplary" menus obtain a high score [23].

The AHEI-2010 was created as an alternative to the HEI; this index was designed to incorporate foods and nutrients that have been consistently associated with chronic disease risk [24]. It includes vegetables, fruits, whole grains, sugar-sweetened beverages (including fruit juices), nuts/legumes, red/processed meat, trans fat, long-chain omega-3 fatty acids, polyunsaturated fat, sodium, and alcohol (detailed in Additional file 1: Table S1); the score ranges from 0 to 110 .

The aMDS is an index that characterizes traditional food patterns of Mediterranean countries. We used a modified version of the original MDS constructed by Trichopoulou and colleagues [25]. The aMDS considers consumption of certain fatty acids, legumes, cereals, fruits, nuts, vegetables, meat, dairy, and alcohol and ranges from 0 to 10 (Additional file 1: Table S1).

\section{Assessment of covariates}

We collected extensive information on potential covariates, including demographic characteristics, body mass index (BMI), parity, oral contraceptive use, menopausal status, HT use, tubal ligation, caffeine intake, family history of ovarian cancer (in first degree family members), and other lifestyle factors. In general, most covariates were updated every 2-4 years.

\section{Identification of ovarian cancer cases}

Ovarian cancer cases were identified either by self-report of the disease on a biennial questionnaire or through family members, the postal service, or the National Death Index. Women or their next of kin were asked for permission to obtain and review pathology reports to confirm the diagnosis and classify cancers by behavior (invasive vs. borderline), histologic type (e.g. epithelial vs. not; serous/poorly differentiated, endometrioid, clear cell, mucinous, other), and stage. For cases without medical records we attempted to confirm the diagnosis through the appropriate state cancer registry. We compared the pathology report histology with a review of slides by a gynecologic pathologist for 215 cases. The concordance was $98 \%$ for morphology and $83 \%$ for histology [26].

\section{Statistical analyses}

At baseline we excluded women diagnosed with any cancer other than non-melanoma skin cancer $(n=8,458)$, women who reported a prior bilateral oophorectomy $(n=14,418)$, 
or menopause due to pelvic irradiation $(n=90)$. In addition, 1,448 NHS participants died before start of follow-up in 1986. Lastly, participants who did not complete the 1984 FFQ, had an implausible caloric intake in $1984(<600$ or $>3,500 \mathrm{kcal} / \mathrm{d}$ ), or left more than 70 items blank on the 1984 FFQ as well as participants who did not have dietary score data available in 1984 $(n=31,573)$ did not enter the analysis until they had valid dietary data. Participants accrued person-time from the return date of the 1986 questionnaire (or 2 years after the return of the first completed FFQ with plausible caloric intake and no more than 70 items blank) until the earliest of the following events: ovarian cancer diagnosis, any other cancer diagnosis (excluding non-melanoma skin cancer), bilateral oophorectomy, pelvic irradiation, death, or the end of follow-up (June 1, 2010).

Our primary exposure variables were cumulatively averaged diet scores (in quintiles) assessed at least 2 years before diagnosis (i.e., a 2-year lag) to account for potential influences of subclinical disease on dietary patterns. With this method, we used the diet score values from 1984 as the exposure for the follow-up period from 1986 to 1988 , the average of the 1984 and 1986 values as the exposure for 1988 to 1992, the average of the 1984, 1986, and 1990 values as the exposure for 1992 to 1996, and so on. This approach allows the evaluation of long-term dietary intake with reduced measurement error, but maintaining true variations in diet [20]. We tested for linear trends using the medians of the quintile dietary scores as an ordinal variable.

We used Cox proportional hazards models, to estimate hazard ratios (HRs) and 95\% confidence intervals (CIs) associated with quintiles of diet-quality scores. We handled time-varying covariates using the Andersen-Gill data structure [27], with covariate values set at the time the questionnaire was returned. To control for confounding by age, calendar time, and any 2 -way interactions, we stratified jointly by age at the start of each follow-up period and calendar year of each follow-up period. The time scale was in months since the return date for each follow-up period. We tested proportional hazards assumptions using likelihood ratio tests comparing models with and without age $(\leq 60,>60)$ interaction terms, p-values were $0.74,0.97$, and 0.88 for AHEI-2010, HEI2005, and aMDS respectively.

For multivariate models, we adjusted for known and putative risk factors for ovarian cancer, including age (months), total energy intake $(\mathrm{kcal} / \mathrm{d})$, family history of ovarian cancer (yes, no), tubal ligation (yes, no), BMI $\left(\mathrm{kg} / \mathrm{m}^{2}\right)$, parity (yes, no), number of additional pregnancies (continuous), oral contraceptive use duration $(0,>0$ 1 yrs, >1-5 yrs, and >5 yrs), smoking (pack-years), menopausal status (premenopausal/unknown, postmenopausal), type and duration of $\mathrm{PMH}$ use (never $\mathrm{PMH}$ user, past estrogen only user $<5$ yrs, past estrogen only user $\geq 5$ yrs, current estrogen only user $<5$ yrs, current estrogen only user $\geq 5$ yrs, past $E+P$ user $<5$ yrs, past $\mathrm{E}+\mathrm{P}$ user $\geq 5$ yrs, current $\mathrm{E}+\mathrm{P}$ user $<5 \mathrm{yrs}$, and current $\mathrm{E}+\mathrm{P}$ y user $\geq 5$ yrs, past other user $<5$ yrs, past other user $\geq 5$ yrs, current other user $<5$ yrs, and current other user $\geq 5 \mathrm{yrs}$,), age at menarche (years), hysterectomy (no, yes, unknown), unilateral oophorectomy (no, yes, unknown), lactose intake (g/d), caffeine intake $(\mathrm{mg} / \mathrm{d})$, and physical activity $(0-3.8,>3.8-11.1,>11.1$ 26.4, >26.4 MET-hrs/wk, missing).

Secondarily, we evaluated the relations between dietary scores and specific subtypes of ovarian cancer using competing risk proportional hazards models [28], including invasive versus borderline, serous and poorly differentiated versus non-serous, and rapidly fatal (death from ovarian cancer within 3 years of diagnosis) versus less aggressive [29]. The estimates for the dietary scores, as well as tubal ligation, parity, and estrogen only HT use, were allowed to vary by subtype based on prior analyses, whereas estimates for the remaining covariates were constrained to a single effect estimate across subtypes. To test for heterogeneity by tumor subtype, we compared a model allowing the association for each dietary score to vary by subtype to a model that with the same association for all tumors. Analyses were conducted in SAS9.3 (SAS Institute, Cary, NC, USA) and all analyses used two-sided p-values.

\section{Results}

We documented 696 incident epithelial ovarian cancer cases over 24 years of follow-up among 82,948 women. At the midpoint of follow-up (1998), women with a high AHEI-2010 score had lower BMI, higher physical activity, lower caffeine intake, higher lactose intake, and smoked less than those with lower scores (Table 1). Similar results were observed for the HEI-2005 and aMDS (Additional file 2: Table S2 and Additional file 3: Table S3). Based on the 1984 FFQ, the correlation was $0.63(P<.0001)$ between HEI-2005 and AHEI-2010 scores, $0.43(P<.0001)$ between HEI-2005 and aMDS, and $0.56(P<.0001)$ between AHEI-2010 and aMDS.

Overall, the AHEI-2010 was not statistically significantly associated with epithelial ovarian cancer risk (Ptrend $=0.77$ ). Compared to women with AHEI-2010 $\leq$ 42 , the multivariate adjusted HRs $(95 \% \mathrm{CI})$ were 1.02 (0.78-1.32) for AHEI-2010>42-48, 1.23 (0.96-1.59) for AHEI-2010 > 48-53, 1.11 (0.86-1.43) for AHEI-2010> 53-59, and 1.03 (0.80-1.34) for AHEI-2010 > 59 (Table 2). The associations were similar by invasive versus borderline, serous/poorly differentiated versus non-serous, and rapidly fatal versus less aggressive tumors, ( $P$ heterogeneity $=0.91,0.98$, and 0.71 , respectively) and when we restricted to women without a family history of ovarian cancer. 
Table 1 Selected participant characteristics in 1998, the midpoint during follow-up, by quintiles of AHEI-2010 score among women in the NHS

\begin{tabular}{|c|c|c|c|c|c|}
\hline & \multicolumn{5}{|c|}{ Quintiles of AHEI-2010 score } \\
\hline & $\leq 42(\mathrm{~N}=11255)$ & $>42-48(\mathrm{~N}=12518)$ & $>48-53(\mathrm{~N}=13169)$ & $>53-59(\mathrm{~N}=13417)$ & $>59(\mathrm{~N}=13273)$ \\
\hline \multicolumn{6}{|l|}{ Mean (SD) } \\
\hline Age, years ${ }^{*}$ & $62.4(7.1)$ & $63.4(7.1)$ & $64.1(7.1)$ & $64.8(7.1)$ & $65.6(7.0)$ \\
\hline Age at menarche, years ${ }^{*}$ & $12.6(1.4)$ & $12.6(1.4)$ & $12.5(1.4)$ & $12.5(1.4)$ & $12.5(1.4)$ \\
\hline $\mathrm{BMI}, \mathrm{kg} / \mathrm{m}^{2}$ & $27.0(5.5)$ & 26.8 (5.2) & $26.7(5.2)$ & $26.5(5.0)$ & $26.0(4.9)$ \\
\hline Years of OC use $\mathrm{e}^{\mathrm{a}}$ & $4.4(3.8)$ & $4.3(3.8)$ & $4.2(3.9)$ & $4.1(3.9)$ & $4.1(4.0)$ \\
\hline Parity $^{\mathrm{b}}$ & $3.3(1.6)$ & $3.3(1.6)$ & $3.2(1.5)$ & $3.2(1.5)$ & $3.1(1.4)$ \\
\hline Physical activity, MET-hr/wk & $12.5(17.4)$ & $14.9(18.3)$ & $17.2(21.6)$ & $18.9(21.6)$ & $23.8(27.0)$ \\
\hline Lactose intake, mg/day & $12.7(9.6)$ & $13.2(9.1)$ & $13.6(9.2)$ & $14(9.3)$ & $13.9(9.0)$ \\
\hline Caffeine intake, mg/day & $287.9(201.6)$ & $291.6(202.0)$ & $285.5(199.4)$ & $278.9(198.8)$ & $259.7(198.3)$ \\
\hline Calories per day & $1859(451)$ & $1777(460)$ & $1739(465)$ & $1705(468)$ & $1684(461)$ \\
\hline Pack-years of smoking ${ }^{c}$ & $31.8(24.5)$ & $27.6(22.6)$ & $25.3(21.3)$ & $22.7(20.0)$ & $20.5(18.4)$ \\
\hline E only HT use, years ${ }^{d}$ & $6.0(5.6)$ & $6.0(5.7)$ & $6.4(6.0)$ & $6.4(5.8)$ & $6.6(5.9)$ \\
\hline$E+P H T$ use, years ${ }^{e}$ & $5.0(3.2)$ & $5.0(3.3)$ & $5.2(3.3)$ & $5.2(3.4)$ & $5.3(3.5)$ \\
\hline Other HT use, years ${ }^{f}$ & $3.0(2.9)$ & $2.9(2.8)$ & $3.0(2.7)$ & $3.0(2.6)$ & $3.1(2.7)$ \\
\hline \multicolumn{6}{|l|}{ Percent } \\
\hline Ever OC use & 49 & 49 & 51 & 51 & 52 \\
\hline \multicolumn{6}{|l|}{ Smoking status } \\
\hline Never & 47 & 45 & 44 & 42 & 40 \\
\hline Past & 36 & 41 & 43 & 47 & 53 \\
\hline Current & 17 & 14 & 12 & 10 & 7 \\
\hline Parous & 95 & 95 & 95 & 94 & 93 \\
\hline Family history of ovarian cancer & 3 & 3 & 3 & 3 & 3 \\
\hline Tubal ligation & 21 & 21 & 21 & 21 & 21 \\
\hline \multicolumn{6}{|l|}{ Hysterectomy } \\
\hline No & 73 & 75 & 74 & 75 & 74 \\
\hline Yes & 22 & 21 & 23 & 22 & 22 \\
\hline Unknown & 5 & 4 & 3 & 3 & 3 \\
\hline \multicolumn{6}{|l|}{ Unilateral oophorectomy } \\
\hline No & 85 & 87 & 86 & 87 & 87 \\
\hline Yes & 9 & 8 & 9 & 9 & 8 \\
\hline Unknown & 6 & 5 & 4 & 4 & 4 \\
\hline Postmenopausal & 92 & 92 & 93 & 93 & 92 \\
\hline Ever E only HT use & 22 & 23 & 25 & 25 & 27 \\
\hline Ever $\mathrm{E}+\mathrm{P}$ HT use & 26 & 29 & 32 & 33 & 36 \\
\hline Ever other HT use & 18 & 20 & 21 & 22 & 25 \\
\hline
\end{tabular}

Values are standardized to the age distribution of the study population. Values of polytomous variables may not sum to $100 \%$ due to rounding.

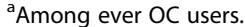

${ }^{\mathrm{b}}$ Among parous women.

cAmong ever smokers.

${ }^{\mathrm{d}}$ Among $\mathrm{E}$ only $\mathrm{HT}$ ever users.

${ }^{\mathrm{e}}$ Among $\mathrm{E}+\mathrm{P} \mathrm{HT}$ ever users.

${ }^{f}$ Among other HT ever users.

*Value is not age adjusted. 
Table 2 Hazard ratios (95\% confidence intervals) for the association between 2-year lagged cumulative updated AHEI-2010 and ovarian cancer from 1986 through 2010 among women in the NHS

\begin{tabular}{|c|c|c|c|c|c|c|c|}
\hline & \multirow[b]{2}{*}{$\mathrm{N}$ cases } & \multicolumn{6}{|c|}{ AHEI-2010 } \\
\hline & & $\leq 42$ & $>42-48$ & $>48-53$ & $>53-59$ & $>59$ & $P$ trend \\
\hline \# of cases & & 106 & 125 & 159 & 153 & 153 & \\
\hline Person-years & & 294,805 & 294,224 & 293,771 & 293,500 & 293,282 & \\
\hline Age-adjusted & 696 & 1.00 (Ref) & $1.04(0.80,1.35)$ & $1.29(1.00,1.65)$ & $1.17(0.91,1.50)$ & $1.12(0.87,1.45)$ & 0.30 \\
\hline Multivariable & 696 & 1.00 (Ref) & $1.02(0.78,1.32)$ & $1.23(0.96,1.59)$ & $1.11(0.86,1.43)$ & $1.03(0.80,1.34)$ & 0.77 \\
\hline Invasive ${ }^{*}$ & 592 & 1.00 (Ref) & $1.10(0.83,1.46)$ & $1.34(1.02,1.76)$ & $1.17(0.88,1.54)$ & $1.00(0.75,1.34)$ & 0.90 \\
\hline Borderline* & 57 & 1.00 (Ref) & $0.72(0.32,1.67)$ & $0.79(0.34,1.83)$ & $0.87(0.39,1.95)$ & $0.87(0.38,1.95)$ & 0.88 \\
\hline Serous/poorly differentiated* & 435 & 1.00 (Ref) & $1.19(0.86,1.65)$ & $1.32(0.96,1.82)$ & $1.17(0.84,1.62)$ & $0.99(0.71,1.39)$ & 0.69 \\
\hline Non-serous* & 148 & 1.00 (Ref) & $0.65(0.37,1.12)$ & $0.93(0.56,1.53)$ & $0.79(0.47,1.33)$ & $0.87(0.53,1.44)$ & 0.83 \\
\hline Rapidly fatal* & 247 & 1.00 (Ref) & $1.11(0.72,1.70)$ & $1.18(0.78,1.80)$ & $1.06(0.70,1.63)$ & $0.93(0.61,1.44)$ & 0.60 \\
\hline Less aggressive* & 274 & 1.00 (Ref) & $1.15(0.76,1.74)$ & $1.55(1.05,2.29)$ & $1.24(0.82,1.86)$ & $1.02(0.66,1.55)$ & 0.98 \\
\hline
\end{tabular}

*Adjustment factors are listed in the statistical analyses section.

$P$ values for heterogeneity by tumor subtype were $0.91,0.98$, and 0.71 for invasive versus borderline, serous/poorly differentiated versus non-serous, and rapidly fatal versus less aggressive tumors, respectively.

No clear associations were observed for the HEI-2005 (Table 3) or the aMDS (Table 4) and ovarian cancer risk or by tumor subtype. For example, women with HEI$2005>74$ versus $\leq 56$ [i.e., top versus bottom quintile] had a HR of $0.85(95 \% \mathrm{CI}=0.65-1.12, P$ trend $=0.57)$ and women with aMDS $>5.5$ versus $\leq 2.6$, the $H R$ was $0.91(95 \% \mathrm{CI}=0.71-1.18$; $P$ trend $=0.44)$. No heterogeneity was observed comparing different ovarian cancer subtypes for the HEI-2005 ( $P$ heterogeneity $\geq 0.32)$ or aMDS ( $P$ heterogeneity $\geq 0.41$ ) and the results were similar when restricting to women without a family history of ovarian cancer.

\section{Discussion}

In this large prospective study, we did not observe any clear associations between three diet quality scores and the risk of epithelial ovarian cancer. Further, no association between the diet scores and risk were observed for specific ovarian cancer subtypes defined by invasiveness, histology, or tumor aggressiveness.

Our results are consistent with one small study of the HEI-2005 and ovarian cancer risk, which observed no association [16] and a prospective cohort study of the "Dietary Guidelines for Americans", which also observed no association [30]. Studies using statistical approaches, such as principal components analysis, to assess dietary patterns in the population have not reported consistent associations with ovarian cancer, although there is some evidence that a pattern high in fat and meat may be associated with increased risk [31-34]. Other scores that include body size and physical activity in addition to diet factors inconsistently

Table 3 Hazard ratios (95\% confidence intervals) for the association between 2-year lagged cumulative updated HEI-2005 and ovarian cancer from 1986 through 2010 among women in the NHS

\begin{tabular}{|c|c|c|c|c|c|c|c|}
\hline & \multirow[b]{2}{*}{$\mathrm{N}$ cases } & \multicolumn{6}{|l|}{ HEI-2005 } \\
\hline & & $\leq 56$ & $>56-63$ & $>63-68$ & $>68-74$ & $>74$ & $P$ trend \\
\hline$N$ cases & & 127 & 117 & 129 & 162 & 161 & \\
\hline Person-years & & 294,749 & 294,665 & 294,337 & 293,738 & 292,082 & \\
\hline Age-adjusted & 696 & 1.00 (Ref) & $0.82(0.63,1.05)$ & $0.85(0.66,1.09)$ & $0.99(0.78,1.26)$ & $0.92(0.72,1.17)$ & 0.98 \\
\hline Multivariable* & 696 & 1.00 (Ref) & $0.79(0.61,1.03)$ & $0.82(0.63,1.06)$ & $0.93(0.72,1.20)$ & $0.85(0.65,1.12)$ & 0.57 \\
\hline Invasive ${ }^{*}$ & 592 & 1.00 (Ref) & $0.80(0.60,1.05)$ & $0.80(0.60,1.05)$ & $0.91(0.69,1.20)$ & $0.86(0.64,1.15)$ & 0.60 \\
\hline Borderline* & 57 & 1.00 (Ref) & $1.00(0.45,2.24)$ & $1.11(0.50,2.43)$ & $0.97(0.42,2.20)$ & $0.54(0.20,1.43)$ & 0.31 \\
\hline Serous/poorly differentiated* & 435 & 1.00 (Ref) & $0.81(0.59,1.13)$ & $0.91(0.66,1.25)$ & $0.91(0.66,1.26)$ & $0.90(0.64,1.27)$ & 0.79 \\
\hline Non-serous* & 148 & 1.00 (Ref) & $0.77(0.46,1.31)$ & $0.70(0.41,1.21)$ & $1.03(0.62,1.69)$ & $0.83(0.49,1.43)$ & 0.81 \\
\hline Rapidly fatal* & 247 & 1.00 (Ref) & $0.76(0.51,1.14)$ & $0.62(0.40,0.94)$ & $0.67(0.44,1.02)$ & $0.75(0.50,1.13)$ & 0.15 \\
\hline Less aggressive* & 274 & 1.00 (Ref) & $0.79(0.52,1.18)$ & $0.89(0.60,1.32)$ & $1.08(0.73,1.59)$ & $0.85(0.556,1.29)$ & 0.89 \\
\hline
\end{tabular}

*Adjustment factors are listed in the Statistical Analyses section.

$P$ values for heterogeneity by tumor subtype were $0.42,0.95$, and 0.32 for invasive versus borderline, serous/poorly differentiated versus non-serous, and rapidly fatal versus less aggressive tumors, respectively. 
Table 4 Hazard ratios (95\% confidence intervals) for the association between 2-year lagged cumulative updated aMDS and ovarian cancer from 1986 through 2010 among women in the NHS

\begin{tabular}{|c|c|c|c|c|c|c|c|}
\hline & \multirow[b]{2}{*}{$\mathrm{N}$ cases } & \multicolumn{6}{|l|}{ aMDS } \\
\hline & & $\leq 2.6$ & $>2.6-3.5$ & $>3.5-4.5$ & $>4.5-5.5$ & $>5.5$ & $P$ trend \\
\hline$N$ cases & & 134 & 119 & 148 & 136 & 159 & \\
\hline Person-years & & 290,089 & 247,467 & 329,112 & 293,048 & 309,867 & \\
\hline Age-adjusted & 696 & 1.00 (Ref) & $0.91(0.71,1.17)$ & $0.85(0.67,1.07)$ & $0.86(0.68,1.10)$ & $0.93(0.74,1.18)$ & 0.52 \\
\hline Multivariable* & 696 & 1.00 (Ref) & $0.90(0.70,1.16)$ & $0.83(0.65,1.05)$ & $0.85(0.66,1.09)$ & $0.91(0.71,1.18)$ & 0.44 \\
\hline Invasive* & 592 & 1.00 (Ref) & $0.93(0.71,1.22)$ & $0.80(0.61,1.03)$ & $0.86(0.66,1.13)$ & $0.86(0.65,1.13)$ & 0.25 \\
\hline Borderline $^{*}$ & 57 & 1.00 (Ref) & $0.76(0.33,1.78)$ & $0.93(0.44,1.94)$ & $0.44(0.17,1.15)$ & $0.81(0.37,1.78)$ & 0.37 \\
\hline Serous/poorly differentiated* & 435 & 1.00 (Ref) & $0.95(0.69,1.31)$ & $0.93(0.69,1.26)$ & $0.86(0.63,1.18)$ & $0.87(0.63,1.20)$ & 0.29 \\
\hline Non-serous* & 148 & 1.00 (Ref) & $0.71(0.42,1.19)$ & $0.52(0.31,0.88)$ & $0.72(0.44,1.20)$ & $0.85(0.53,1.38)$ & 0.62 \\
\hline Rapidly fatal* & 247 & 1.00 (Ref) & $0.78(0.51,1.18)$ & $0.71(0.48,1.06)$ & $0.83(0.56,1.23)$ & $0.66(0.44,1.00)$ & 0.11 \\
\hline Less aggressive* & 274 & 1.00 (Ref) & $1.25(0.85,1.84)$ & $0.87(0.59,1.29)$ & $0.88(0.59,1.32)$ & $1.04(0.70,1.55)$ & 0.59 \\
\hline
\end{tabular}

*Adjustment factors are listed in the Statistical Analyses section.

$P$ values for heterogeneity by subtype were $0.63,0.89$, and 0.41 for invasive versus borderline, serous/poorly differentiated versus non-serous, and rapidly fatal versus less aggressive, respectively.

been associated with ovarian cancer risk, with no association in a European cohort [35] and a positive association in a US study [30]. The lack of association between these diet quality indices and ovarian cancer risk is also consistent with prior research that many of the individual components on the score, such as fruits, vegetables and alcohol, were not strongly associated with ovarian cancer risk, even in large pooled analyses [36,37].

The major strengths of our study are the large number of ovarian cancer cases; this enabled us to examine risk by tumor characteristics. We also had comprehensive information on diet and important covariates. All this information was collected prospectively, which reduces the potential for recall bias. In addition, dietary and covariate data were assessed multiple times throughout follow-up, which allows us to use long-term, cumulative average exposures and thus reduce within person variation. To reduce potential reverse causation by sub-clinical ovarian cancer influencing diet, we used a 2-year lagged analysis. Finally, the dietary scores calculated in our study have a wide distribution except for aMDS, suggesting that we have a good representation of different dietary habits in the US.

Several methodological issues should be considered in interpreting our findings. First, the diet scores are calculated using arbitrary weights that are assigned to each component, in part based on research on cardiovascular disease risk. Second, we cannot distinguish brands or processing methods for the food items on the FFQ, which may cause misclassification in nutrient content. Finally, self-reported diet assessed by FFQ has measurement error, even though we validated it with dietary records $[21,38,39]$. We expect the misclassification should be random with respect to the outcome and would lead to attenuation of associations.

Overall, in this large prospective cohort study among US women, we did not observe any clear associations with three scores of diet quality, AHEI-2010, HEI-2005, or aMDS, with the risk of epithelial ovarian cancer, suggesting that current dietary recommendations in the US may not influence ovarian cancer incidence. Given the limited number of ovarian cancer cases in individual cohorts, a pooled analysis of prospective cohorts should be considered to evaluate potential differential associations for more rare tumor subtypes and consideration of other dietary scores that better reflect factors associated with cancer is warranted.

\section{Additional files}

Additional file 1: Table S1. Scoring criteria for AHEl-2010, HEl-2005, and aMDS. All scoring criteria are calculated per 1000 kilocalories/day unless specified, except saturated fat and SoFAAs, which are calculated as percentage of total energy. Polyunsaturated fat does not include EPA or DHA intake. For alcohol, the highest score was assigned to moderate, and the worst score to heavy, alcohol consumers. Nondrinkers received a score of 2.5 .

Additional file 2: Table S2. Selected participant characteristics in 1998, the midpoint during follow-up, by quintiles of HEl-2005 score among women in the NHS. Values are standardized to the age distribution of the study population. Values of polytomous variables may not sum to $100 \%$ due to rounding. a Among ever OC users. b Among parous women. c Among ever smokers. d Among E only HT ever users. e Among E + P HT ever users. $f$ Among other $H T$ ever users. ${ }^{*}$ Value is not age adjusted.

Additional file 3: Table S3. Selected participant characteristics in 1998, the midpoint during follow-up, by quintiles of aMDS score among women in the NHS. Values are standardized to the age distribution of the study population. Values of polytomous variables may not sum to $100 \%$ due to rounding. a Among ever OC users. b Among parous women. c Among ever smokers. d Among E only HT ever users. e Among E + P HT ever users. f Among other HT ever users. * Value is not age adjusted. 


\section{Abbreviations}

HEI-2005: Healthy Eating Index 2005; AHEl-2010: Alternative Healthy Eating Index 2010; aMDS: Alternate Mediterranean Diet Score; FFQ: Food frequency questionnaire; PMH: Postmenopausal hormone use; BMl: Body mass index; HR: Hazard ratio; Cl: Confidence interval.

\section{Competing interests}

The authors declare that they have no conflict of interest. The funders had no role in the design and conduct of the study; collection, management, analysis, and interpretation of the data; and preparation, review, or approval of the manuscript.

\section{Authors' contributions}

All authors of this research paper have directly participated in the planning, execution, or analysis of the study. All authors of this paper have read and approved the final version submitted. JX, EP, and SST contributed to the conduct of the analysis. All authors contributed to the manuscript writing and interpretation of results.

\section{Acknowledgements}

We thank participants of the Nurses' Health Study for their longstanding contributions and support to this study and following state cancer registries for their help: AL, AZ, AR, CA, CO, CT, DE, FL, GA, ID, IL, IN, IA, KY, LA, ME, MD, MA, MI, NE, NH, NJ, NY, NC, ND, OH, OK, OR, PA, RI, SC, TN, TX, VA, WA, WY.

\section{Grant support}

This project was supported by the National Institutes of Health P01CA87969. J. Xie was supported by scholarships from Harvard University.

\section{Author details}

${ }^{1}$ Channing Division of Network Medicine, Department of Medicine, Brigham and Women's Hospital and Harvard Medical School, 181 Longwood Avenue, Boston, MA 02115, USA. ²Department of Epidemiology, Harvard School of Public Health, Boston, MA, USA. ${ }^{3}$ Obstetrics and Gynecology Epidemiology Center, Department of Obstetrics and Gynecology, Brigham and Women's Hospital and Harvard Medical School, Boston, MA, USA. ${ }^{4}$ Department of Nutrition, Simmons College, Boston, MA, USA. ${ }^{5}$ Department of Biostatistics, Harvard School of Public Health, Boston, MA, USA. ${ }^{6}$ Department of Nutrition, Harvard School of Public Health, Boston, MA, USA.

\section{Received: 16 September 2014 Accepted: 26 November 2014}

\section{0.}

\section{References}

1. American Cancer Society: Cancer Facts and Figures. Atlanta: American Cancer Society; 2014.

2. Permuth-Wey J, Sellers TA: Epidemiology of ovarian cancer. Methods Mol Biol 2009, 472:413-437.

3. Dunn JE: Cancer epidemiology in populations of the United Stateswith emphasis on Hawaii and California-and Japan. Cancer Res 1975, 35(11 Pt. 2):3240-3245.

4. Cannistra SA: Cancer of the ovary. N Engl J Med 2004, 351(24):2519-2529.

5. Bandera EV: Nutritional factors in ovarian cancer prevention: what have we learned in the past 5 years? Nutr Cancer 2007, 59(2):142-151.

6. Braem MG, Onland-Moret NC, Schouten LJ, Tjonneland A, Hansen L, Dahm CC, Overvad K, Lukanova A, Dossus L, Floegel A, Boeing H, Clavel-Chapelon F, Chabbert-Buffet N, Fagherazzi G, Trichopoulou A, Benetou V, Goufa I, Pala V, Galasso R, Mattiello A, Sacerdote C, Palli D, Tumino R, Gram IT, Lund E, Gavrilyuk O, Jose Sanchez M, Quirós R, Gonzales CA, Dorronsoro M: Coffee and tea consumption and the risk of ovarian cancer: a prospective cohort study and updated meta-analysis. Am J Clin Nutr 2012, 95(5):1172-1181.

7. Larsson SC, Giovannucci E, Wolk A: Dietary folate intake and incidence of ovarian cancer: the Swedish Mammography Cohort. J Natl Cancer Inst 2004, 96(5):396-402.

8. Schulz M, Lahmann PH, Riboli E, Boeing H: Dietary determinants of epithelial ovarian cancer: a review of the epidemiologic literature. Nutr Cancer 2004, 50(2):120-140.

9. Song YJ, Kristal AR, Wicklund KG, Cushing-Haugen $K L$, Rossing MA: Coffee, tea, colas, and risk of epithelial ovarian cancer. Cancer Epidemiol Biomarkers Prev 2008, 17(3):712-716.
10. Tworoger SS, Gertig DM, Gates MA, Hecht JL, Hankinson SE: Caffeine, alcohol, smoking, and the risk of incident epithelial ovarian cancer. Cancer 2008, 112(5):1169-1177.

11. Gates MA, Vitonis AF, Tworoger SS, Rosner B, Titus-Ernstoff L, Hankinson SE, Cramer DW: Flavonoid intake and ovarian cancer risk in a populationbased case-control study. Int J Cancer 2009, 124(8):1918-1925.

12. Larsson SC, Wolk A: Coffee consumption is not associated with ovarian cancer incidence. Cancer Epidemiol Biomarkers Prev 2005, 14(9):2273-2274.

13. Calder PC, Ahluwalia N, Brouns F, Buetler T, Clement K, Cunningham K, Esposito K, Jönsson SE, Kolb H, Lansink M, Marcos A, Margioris A, Matusheski N, Nordmann H, O’Brien J, Pugliese G, Rizkalla S, Schalkwijk C, Tuomilehto J, Wärnberg J, Watzl B, Winklhofer-Roob BM: Dietary factors and low-grade inflammation in relation to overweight and obesity. Br J Nutr 2011, 106(Suppl 3):S5-S78.

14. Kalupahana NS, Claycombe KJ, Moustaid-Moussa N: (n-3) fatty acids alleviate adipose tissue inflammation and insulin resistance: mechanistic insights. Advances in nutrition 2011, 2(4):304-316.

15. Ness RB, Cottreau C: Possible role of ovarian epithelial inflammation in ovarian cancer. J Natl Cancer Inst 1999, 91(17):1459-1467.

16. Chandran U, Bandera EV, Williams-King MG, Paddock LE, RodriguezRodriguez L, Lu SE, Faulkner S, Pulick K, Olson SH: Healthy eating index and ovarian cancer risk. Cancer Causes Control 2011, 22(4):563-571.

17. Rich-Edwards JW, Corsano KA, Stampfer MJ: Test of the National Death Index and Equifax Nationwide Death Search. Am J Epidemiol 1994, 140(11):1016-1019.

18. Stampfer MJ, Willett WC, Speizer FE, Dysert DC, Lipnick R, Rosner B, Hennekens CH: Test of the National Death Index. Am J Epidemiol 1984, 119(5):837-839.

19. Willett WC, Sampson L, Stampfer MJ, Rosner B, Bain C, Witschi J, Hennekens $\mathrm{CH}$, Speizer FE: Reproducibility and validity of a semiquantitative food frequency questionnaire. Am J Epidemiol 1985, 122(1):51-65.

20. Willett WC: Nutritional Epidemiology. USA: Oxford University Press; 1998.

21. Feskanich D, Rimm EB, Giovannucci EL, Colditz GA, Stampfer MJ, Litin LB, Willett WC: Reproducibility and validity of food intake measurements from a semiquantitative food frequency questionnaire. J Am Diet Assoc 1993, 93(7):790-796

22. Guenther PM, Reedy J, Krebs-Smith SM: Development of the Healthy Eating Index-2005. J Am Diet Assoc 2008, 108(11):1896-1901.

23. Guenther PM, Reedy J, Krebs-Smith SM, Reeve BB: Evaluation of the Healthy Eating Index-2005. J Am Diet Assoc 2008, 108(11):1854-1864.

24. Chiuve SE, Fung TT, Rimm EB, Hu FB, McCullough ML, Wang M, Stampfer MJ, Willett WC: Alternative dietary indices both strongly predict risk of chronic disease. J Nutr 2012, 142(6):1009-1018.

25. Trichopoulou A, Costacou T, Bamia C, Trichopoulos D: Adherence to a Mediterranean diet and survival in a Greek population. N Engl J Med 2003, 348(26):2599-2608

26. Tworoger SS, Hecht JL, Giovannucci E, Hankinson SE: Intake of folate and related nutrients in relation to risk of epithelial ovarian cancer. Am J Epidemiol 2006, 163(12):1101-1111.

27. Therneau TM, Hamilton SA: rhDNase as an example of recurrent event analysis. Stat Med 1997, 16(18):2029-2047.

28. Fine J, Gray R: A proportional hazards model for the subdistribution of a competing risk. J Am Stat Assoc 1999, 94:496-509.

29. Poole EM, Merritt MA, Jordan SJ, Yang HP, Hankinson SE, Park Y, Rosner B, Webb PM, Cramer DW, Wentzensen N, Terry KL, Tworoger SS: Hormonal and reproductive risk factors for epithelial ovarian cancer by tumor aggressiveness. Cancer Epidemiol Biomarkers Prev 2013, 22(3):429-437.

30. Harnack L, Nicodemus K, Jacobs DR Jr, Folsom AR: An evaluation of the Dietary Guidelines for Americans in relation to cancer occurrence. Am J Clin Nutr 2002, 76(4):889-896.

31. Chang ET, Lee VS, Canchola AJ, Clarke CA, Purdie DM, Reynolds P, Anton-Culver H, Bernstein L, Deapen D, Peel D, Pinder R, Ross RK, Stram DO, West DW, Wright W, Ziogas A, Horn-Ross PL: Diet and risk of ovarian cancer in the California Teachers Study cohort. Am J Epidemiol 2007, 165(7):802-813.

32. Edefonti V, Decarli A, La Vecchia C, Bosetti C, Randi G, Franceschi S, Dal Maso L, Ferraroni M: Nutrient dietary patterns and the risk of breast and ovarian cancers. Int J Cancer 2008, 122(3):609-613.

33. Edefonti V, Randi G, Decarli A, Bosetti C, Franceschi S, Dal Maso L, Ferraroni $\mathrm{M}$ : Clustering dietary habits and the risk of breast and ovarian cancers. Ann Oncol 2009, 20(3):581-590. 
34. Kolahdooz F, Ibiebele TI, van der Pols JC, Marks GC, Hughes MC, Whiteman DC, Webb PM, for the Australian Cancer Study (Ovarian Cancer) and the Australian Ovarian Cancer Study Group: Dietary patterns and ovarian cancer risk. Am J Clin Nutr 2009, 89(1):297-304.

35. Romaguera D, Vergnaud AC, Peeters PH, van Gils CH, Chan DSM, Ferrari $P$, Romieu I, Jenab M, Slimani N, Clavel-Chapelon F, Fagherazzi G, Perquier F, Kaaks R, Teucher B, Boeing B, von Rüsten A, Tjønneland A, Olsen A, Dahm CC, Overvad K, Ramón Quirós J, Gonzalez CA, José Sánchez M, Navarro C, Barricarte A, Dorronsoro M, Khaw KT, Wareham NJ, Crowe FL, Key TJ: Is concordance with World Cancer Research Fund/American Institute for Cancer Research guidelines for cancer prevention related to subsequent risk of cancer? Results from the EPIC study. Am J Clin Nutr 2012, 96(1):150-163.

36. Genkinger JM, Hunter DJ, Spiegelman D, Buring JE, Freudenheim JL, Goldbohm RA, Harnack L, Hankinson SE, Larsson SC, Leitzmann M, McCullough ML, Marshall J, Miller AB, Rodriguez C, Rohan TE, Schatzkin A, Schouten $\sqcup$, Wolk A, Zhang SM, Smith-Warner SA: Alcohol intake and ovarian cancer risk: a pooled analysis of 10 cohort studies. $\mathrm{Br} J$ Cancer 2006, 94(5):757-762.

37. Koushik A, Hunter DJ, Spiegelman D, Anderson KE, Arslan AA, Beeson WL, van den Brandt PA, Buring JE, Cerhan JR, Colditz GA, Fraser GE, Freudenheim JL, Genkinger JM, Goldbohm RA, Hankinson SE, Koenig KL, Larsson SC, Leitzmann M, McCullough ML, Miller AB, Patel A, Rohan TE, Schatzkin A, Smit E, Willett WC, Wolk A, Zhang SM, Smith-Warner SA: Fruits and vegetables and ovarian cancer risk in a pooled analysis of 12 cohort studies. Cancer Epidemiol Biomarkers Prev 2005, 14(9):2160-2167.

38. Giovannucci E, Colditz G, Stampfer MJ, Rimm EB, Litin L, Sampson L, Willett WC: The assessment of alcohol consumption by a simple self-administered questionnaire. Am J Epidemiol 1991, 133(8):810-817.

39. Rimm EB, Giovannucci EL, Stampfer MJ, Colditz GA, Litin LB, Willett WC: Reproducibility and validity of an expanded self-administered semiquantitative food frequency questionnaire among male health professionals. Am J Epidemiol 1992, 135(10):1114-1126. discussion 1127-36.

doi:10.1186/s13048-014-0112-4

Cite this article as: Xie et al:: A prospective cohort study of dietary indices and incidence of epithelial ovarian cancer. Journal of Ovarian Research 2014 7:112.

\section{Submit your next manuscript to BioMed Central and take full advantage of:}

- Convenient online submission

- Thorough peer review

- No space constraints or color figure charges

- Immediate publication on acceptance

- Inclusion in PubMed, CAS, Scopus and Google Scholar

- Research which is freely available for redistribution 